Keywords: microRNA; hypopharyngeal squamous cell carcinoma; miR-451a; tumour suppressor; ESDN/DCBLD2; expression signature

\title{
Identification of tumour suppressive microRNA-451a in hypopharyngeal squamous cell carcinoma based on microRNA expression signature
}

\author{
I Fukumoto ${ }^{1,2}$, T Kinoshita ${ }^{1,2}$, T Hanazawa $^{2}$, N Kikkawa ${ }^{2}$, T Chiyomaru ${ }^{3}$, H Enokida $^{3}$, N Yamamoto ${ }^{1}$, Y Goto $^{1}$, \\ R Nishikawa1, M Nakagawa ${ }^{3}$, Y Okamoto $^{2}$ and N Seki ${ }^{*, 1}$ \\ ${ }^{1}$ Department of Functional Genomics, Chiba University Graduate School of Medicine, Chiba, Japan; ${ }^{2}$ Department of \\ Otorhinolaryngology/Head and Neck Surgery, Chiba University Graduate School of Medicine, Chiba, Japan and ${ }^{3}$ Department \\ of Urology, Graduate School of Medical and Dental Sciences, Kagoshima University, Kagoshima, Japan
}

Background: Hypopharyngeal squamous cell carcinoma (HSCC) has a very poor prognosis because of its high rates of regional and distant metastasis. Identification of differentially expressed miRNAs and their regulated molecular targets in tumour cells might enhance our understanding of the molecular mechanisms of metastasis in human cancers.

Methods: A HSCC miRNA signature was constructed by array-based methods. Functional studies of microRNA-451a (miR-451a) and target genes were performed to investigate cell proliferation, migration and invasion by cancer cell lines. To identify miR-451a-regulated molecular targets, we adopted gene expression analysis and in silico database analysis.

Results: Our miRNA signature revealed that miR-451a was significantly downregulated in HSCC. Restoration of miR-451a in cancer cell lines revealed that this miRNA significantly inhibited cancer cell migration and invasion. Our data demonstrated that the gene coding for endothelial and smooth muscle cell-derived neuropilin-like molecule (ESDN/DCBLD2) was a direct target of miR-451a regulation. Silencing of ESDN inhibited cell migration and invasion by cancer cells.

Conclusions: Loss of tumour suppressive miR-451a enhanced cancer cell migration and invasion in HSCC through direct regulation of ESDN. Our miRNA signature and functional analysis of targets regulated by tumour suppressive miR-451a provide new insights into the potential mechanisms of HSCC oncogenesis and metastasis.

Head and neck squamous cell carcinoma (HNSCC) is the sixth most common cancer in the world and $\sim 500000$ cases are diagnosed every year (Jemal et al, 2010). Hypopharyngeal squamous cell carcinoma (HSCC) occurs less frequently and accounts for 3-5\% of all HNSCC (Hall et al, 2008; Cooper et al, 2009). In spite of considerable advances in multimodality therapy, including surgery, radiotherapy and chemotherapy, the overall survival rate for patients with HSCC is only 15-45\% (Takes et al, 2012; Chan \& Wei, 2013). Patients with HSCC are usually diagnosed at a late stage and local tumour recurrence and distant metastasis occur after conventional therapies (Takes et al, 2012; Chan and Wei, 2013). Recurrence is the primary cause for poor survival of HSCC. Therefore, understanding the molecular mechanisms of metastatic pathways underlying HSCC using currently available genomic approaches might improve therapies for and prevention of the disease.

The discovery of non-coding RNAs (ncRNAs) in the human genome was an important conceptual breakthrough in 
the post-genome sequencing era (Carthew and Sontheimer, 2009). Further improving our understanding of ncRNAs is necessary for continued progress in cancer research. MicroRNAs (miRNAs) are endogenous small ncRNA molecules (19-22 bases in length) that regulate protein-coding gene expression by repressing translation or cleaving RNA transcripts in a sequence-specific manner (Bartel, 2004). Numerous studies have shown that miRNAs are aberrantly expressed in many human cancers and that they have significant roles in the initiation, development and metastasis of those cancers (Filipowicz et al, 2008; Hobert, 2008; Friedman et al, 2009; Iorio and Croce, 2009). Moreover, normal regulatory mechanisms can be disrupted by the aberrant expression of tumour suppressive or oncogenic miRNAs in cancer cells (Esquela-Kerscher and Slack, 2006; Kwak et al, 2010). Therefore, identification of aberrantly expressed miRNAs is an important first step toward elucidating miRNAmediated oncogenic pathways.

With those points in mind, we have constructed miRNA expression signatures of HSCC using clinical specimens. Using those data, we have investigated the specific roles of miRNAs in HSCC metastasis by examining the differentially expressed miRNAs. Data from our present HSCC signature showed that $m i R-451 a$ is significantly downregulated in cancer tissues, suggesting that miR-451a might act as a tumour suppressor. Several studies reported aberrant expression of miR-451a in several types of human cancers (Pan et al, 2013). Furthermore, the expression levels of $m i R-451 a$ are associated with the clinical outcome in several types of cancer, including lung cancer, oesophageal cancer and nasopharyngeal cancer (Wang et al, 2011, 2013; Liu et al, 2013). These data indicated that miR-451a might have critical roles in cancer cells and oncogenesis. However, the functional role of miR-451a in HSCC is unknown.

The aim of the present study was to investigate the functional significance of miR-451a and to identify the molecular targets regulated by the miRNAs in HSCC cells. Our data demonstrated that restoration of mature $m i R-451 a$ inhibited cancer cell migration and invasion. Moreover, gene expression data and in silico database analysis showed that the gene coding for endothelial and smooth muscle cell-derived neuropilin-like molecule (ESDN/DCBLD2), a novel neuropilin-like membrane protein, was a potential target of miR-451a-mediated regulation. Silencing studies of the ESDN/DCBLD2 gene significantly inhibited cell migration and invasion of cancer cells. The discovery of tumour suppressive $m i R-451 a$-regulated targets provides new insight into the potential mechanisms of HSCC oncogenesis and suggests novel therapeutic strategies for the treatment of the disease.

\section{MATERIALS AND METHODS}

Clinical HSCC specimens and RNA isolation. A total of 22 pairs of primary tumours and corresponding normal epithelial specimens were obtained from patients with HSCC at Chiba University Hospital (Chiba, Japan) from 2007 to 2013. The fresh specimens were immediately immersed in RNAlater (Qiagen, Valencia, CA, USA) and stored at $-20^{\circ} \mathrm{C}$ until RNA was extracted. The noncancerous specimens were macroscopically normal and were confirmed to be free of cancer cells by microscopic pathological examination. The patients' backgrounds and clinicopathological characteristics are summarised in Table 1. The patients were classified according to the 2002 Union for International Cancer TNM staging criteria before treatment.

Written consent for tissue donation for research purposes was obtained from each patient before tissue collection. The protocol was approved by the Institutional Review Board of Chiba University.

\begin{tabular}{|c|c|c|c|c|c|c|c|}
\hline No & Age & Sex & T & $\mathbf{N}$ & M & Stage & Differentiaion \\
\hline 1 & 66 & Male & 2 & $2 c$ & 0 & IVA & Moderate \\
\hline 2 & 64 & Female & $4 a$ & 1 & 0 & IVA & Poor \\
\hline 3 & 53 & Male & 2 & $2 b$ & 0 & IVA & Moderate \\
\hline 4 & 59 & Male & 3 & $2 b$ & 0 & IVA & Poor \\
\hline 5 & 66 & Male & $4 a$ & $2 c$ & 0 & IVA & Well \\
\hline 6 & 58 & Female & $4 a$ & $2 c$ & 0 & IVA & Moderate \\
\hline 7 & 52 & Male & $4 a$ & 1 & 1 & IVC & Moderate \\
\hline 8 & 74 & Male & $4 a$ & $2 c$ & 0 & IVA & Poor \\
\hline 9 & 45 & Male & $4 a$ & $2 c$ & 0 & IVA & Moderate \\
\hline 10 & 64 & Female & $4 a$ & 0 & 0 & IVA & Well \\
\hline 11 & 75 & Male & $4 a$ & $2 c$ & 0 & IVA & Well \\
\hline 12 & 76 & Male & $4 a$ & 1 & 0 & IVA & Well \\
\hline 13 & 68 & Male & $4 a$ & 0 & 0 & IVA & Moderate \\
\hline 14 & 73 & Male & 3 & 1 & 0 & III & Poor \\
\hline 15 & 65 & Male & 3 & 0 & 0 & III & Moderate \\
\hline 16 & 71 & Male & 2 & $2 b$ & 0 & IVA & Poor \\
\hline 17 & 64 & Male & 2 & 0 & 0 & II & Moderate \\
\hline 18 & 55 & Male & 3 & $2 b$ & 0 & IVA & Moderate \\
\hline 19 & 71 & Male & $4 a$ & $2 b$ & 0 & IVA & Moderate \\
\hline 20 & 66 & Male & $4 b$ & $2 c$ & 0 & IVB & Moderate \\
\hline 21 & 64 & Male & 2 & 0 & 0 & II & Moderate \\
\hline 22 & 58 & Male & $4 a$ & 0 & 0 & IVA & Well \\
\hline
\end{tabular}

Total RNA was isolated using the TRIzol regimen (Invitrogen, Carlsbad, CA, USA) according to the manufacturer's protocol. RNA quality was confirmed using an Agilent 2100 Bioanalyzer (Agilent technologies, Santa Clara, CA, USA).

Construction of the miRNA expression signature of HSCC. To identify differentially expressed miRNAs in HSCC, $250 \mathrm{ng}$ of total RNA was subjected to microarray analysis using a miRCURY LNA microRNA Array (Exiqon, Vedbaek, Denmark). Labelling, hybridisation, washing and scanning of the microarray were performed by Cosmo Bio (Tokyo, Japan) following the instructions of the manufacturer. Hy3 (sample) signals were normalised by division using the Hy5 (Universal reference) signal. Then, each signal value of the unique probe ID was calculated from the average of the $\mathrm{Hy} 3 / \mathrm{Hy} 5$ normalised signal intensities of quadruplicate probes.

Quantitative real-time reverse transcription polymerase chain reaction (RT-PCR). The procedure for PCR quantification was carried out as previously described (Kikkawa et al, 2010; Nohata et al, 2011a; Kinoshita et al, 2013). The expression levels of $m i R-$ 451a (Assay ID: 001141; Applied Biosystems, Foster City, CA, USA) were analysed by TaqMan quantitative real-time PCR (TaqMan MicroRNA Assay; Applied Biosystems) and normalised to RNU6B (Assay ID: 001093). TaqMan probes and primers for ESDN/DCBLD2 (P/N: Hs00294635_m1) and GUSB (P/N: Hs00939627_ml; an internal control) were used for expression level determination of HSCC clinical specimens. All reactions were performed in triplicate, and each assay included negative control reactions that lacked cDNA.

Transfections with mature miRNA and small-interfering RNA (siRNA). The following mature miRNAs species were used in this study: mirVana miRNA mimic for hsa-miR-451a (Product ID: MC10286) (Applied Biosystems). The following siRNAs were used: Stealth Select RNAisiRNA; si-ESDN/DCBLD2 (Cat no.HSS134348) 
and negative control miRNA/siRNA (P/N: AM17111, Applied Biosystems). RNAs were incubated with OPTI-MEM (Invitrogen) and Lipofectamine RNAiMax reagent (Invitrogen) as described previously. The transfection efficiency of miRNA in cell lines was confirmed based on downregulation of TWF1 (PTK9) mRNA following transfection with $m i R-1$ as previously reported(Kikkawa et al, 2010).

Cell proliferation, migration and invasion assays. To investigate the functional significance of $m i R-451 a$ or si-ESDN/DCBLD2, we performed cell proliferation, migration and invasion assays using $\mathrm{FaDu}$ and SAS cells. The experimental procedures were performed as described in our previous studies (Kinoshita et al, 2013).

Genome-wide gene expression and in silico analysis for the identification of genes regulated by miR-451a. The TargetScan database (Release 6.2; http://www.targetscan.org/) was used for in silico identification of candidate target genes that contained miR-451a targets sites in their $3^{\prime}$-untranslated ( $3^{\prime}$-UTR) region. To identify miR-451a-regulated genes, we used genome-wide gene expression analysis of $\mathrm{FaDu}$ cells transfected with miR-451a. SurePrint G3 Human GE 60K Microarray (Agilent Technologies) was used for expression profiling of $m i R-451 a$ transfectants in comparison with negative control miRNA transfectants.

Western blotting. Cells were harvested $72 \mathrm{~h}$ after transfection, and lysates were prepared. Fifty micrograms of protein from each lysate was separated on Mini-PROTEAN TGX gels (Bio-Rad, Hercules, CA, USA) and transferred to PVDF membranes. Immunoblotting was performed with rabbit anti-DCBLD2 antibodies $(1: 100$; HPA016909; Sigma-Aldrich, St Louis, MO, USA), and antiGAPDH antibodies ( $1: 1000$; ab8245, Abcam, Cambridge, UK) were used as an internal loading control.

Plasmid construction and dual-luciferase reporter assays. The partial wild-type sequences of the ESDN/DCBLD2 3'-UTR or those with deleted miR-451a target sites (positions 2756-2762 of ESDN/ DCBLD2 $3^{\prime}$-UTR) were inserted between the XhoI-Pmel restriction sites in the $3^{\prime}$-UTR of the hRluc gene in the psiCHECK-2 vector (C8021, Promega, Madison, WI, USA). The sequences of the oligonucleotides are described in Supplementary Document 1. SAS cells were transfected with $50 \mathrm{ng}$ of vector and $10 \mathrm{nM}$ of $\mathrm{miR}-451 \mathrm{a}$ using Lipofectamine 2000 (Invitrogen). The activities of firefly and Renilla luciferases in cell lysates were determined with dualluciferase assay systems (E1910; Promega) as described previously (Kikkawa et al, 2010; Nohata et al, 2011a; Kinoshita et al, 2013).

Statistical analysis. The relationships between two groups and the numerical values obtained by real-time PCR were analysed using the paired $t$-test. Spearman's rank test was used to evaluate the correlation between the expression of $m i R-451 a$ and target genes. The relationship among more than three variables and numerical values were analysed using the Bonferroni adjusted Mann-Whitney $U$-test. All analyses were performed using Expert Stat View (version 4, SAS Institute Inc., Cary, NC, USA).

\section{RESULTS}

Differentially expressed miRNAs in HSCC clinical specimens identified by miRNA expression signature analysis. We conducted miRNA expression signature analysis in HSCC clinical specimens (11 pairs of HSCC tissues and corresponding normal tissues, patient numbers 1-11) (Table 1). Expression signatures revealed that 3 miRNAs were upregulated and 23 miRNAs were downregulated in HSCC tissues (Table 2). Entries from the gene expression data in this analysis were approved by GEO, and were assigned GEO accession number GSE51129.
Our expression signature showed that three miRNAs ( $m i R-21$ $5 p, m i R-4732-5 p$ and $m i R-4776-3 p$ ) were upregulated (Fold-change $>2.0$ ) in HSCC tissues.

As for downregulated miRNAs, the top four (miR-1, miR-133a, $m i R-133 b$ and $m i R-29 c)$ were described in our previous reports as tumour suppressive miRNAs in various types of cancers including HNSCC (Table 2) (Nohata et al, 2011b, 2012; Kinoshita et al, $2012 b, 2013)$. In this study, we focused on $m i R-451 a$ and functional studies were performed.

Expression levels of miR-451a in HSCC clinical specimens and cell lines. To validate our miRNA signature results, we evaluated the expression levels of $m i R-451 a$ in 22 HSCC specimens (patient numbers 1-22)(Table 1). Quantitative stem-loop RT-PCR demonstrated that $m i R-451 a$ expression was significantly lower in clinical HSCC specimens and cell lines (FaDu and SAS) compared with noncancerous specimens (Figure 1A). There was no significant correlation between miR-451a expression and various tested clinicopathological parameters of HSCC (data not shown).

Effect of restoring $m i R-451 a$ expression on cell proliferation, migration and invasion activities in cancer cell lines. To investigate the functional effects of $m i R-451 a$, we performed gain-of-function studies using miRNA transfection of $\mathrm{FaDu}$ and SAS cell lines.

The XTT assay demonstrated that cell proliferation was not inhibited in FaDu cells transfected with miR-451a, whereas SAS cells were significantly slowed by transfection in comparison with the mock or miR-control transfectants (Figure 1B). However, cell migration activity was significantly inhibited by miR-451a transfection of both cell lines compared with mock- or miRcontrol-transfected cells (Figure 1C). Moreover, in the Matrigel invasion assays, transfection with $m i R-451 a$ significantly inhibited invasion compared with mock- or miR-control-transfected cells (Figure 1D).

Identification of candidate genes targeted by $m i R-451 a$ in HSCC. To identify genes targeted by $m i R-451 a$, we analysed in silico and gene expression data in miR-451a transfectants. First, we selected miR-451a target genes that contained putative binding sites in their $3^{\prime}$ UTR regions as determined by the TargetScan database. A total of 397 genes were identified in this selection. Next, we performed genome-wide gene expression analysis using a cancer cell line $(\mathrm{FaDu})$ and selected downregulated genes $\left(\log _{2}\right.$ ratio $<-1.0$ ) by $m i R-451 a$ transfection compared with miRcontrol transfection. Among 397 putative candidate genes, 5 genes (SPC25, MIF, ESDN/DCBLD2, C4orf46 and AKR1B1) were downregulated by $m i R-451 a$ transfection in cancer cells (Table 3 ). Entries from the gene expression data of $m i R-451 a$ transfection into $\mathrm{FaDu}$ cells was approved by GEO, and was assigned GEO accession number GSE56243.

We further investigated the expression levels of these five genes in HSCC clinical specimens. Our data showed that three genes (SPC25, ESDN/DCBLD2 and AKR1B1) were significantly upregulated in cancer tissues compared with normal tissues (Figure 2). Spearman's rank test showed a negative correlation between the expression of $m i R-451 a$ and those of the three genes (Figure 3).

Among these candidates, we focused on the ESDN/DCBLD2 gene because it was the most significantly upregulated in cancer tissues. Thus, we examined the functions and characteristics of $E S D N / D C B L D 2$ in further analyses.

ESDN/DCBLD2 was a direct target of $m i R-451 a$ in HSCC cells. We performed quantitative real-time RT-PCR and western blotting in FaDu and SAS cells to investigate whether restoration of $m i R-451 a$ altered $E S D N / D C B L D 2$ gene and protein expression. The mRNA and protein expression levels of ESDN/DCBLD2 were significantly repressed in miR-451a transfectants compared with mock- or miR-control-transfected cells (Figure 4A and B). 


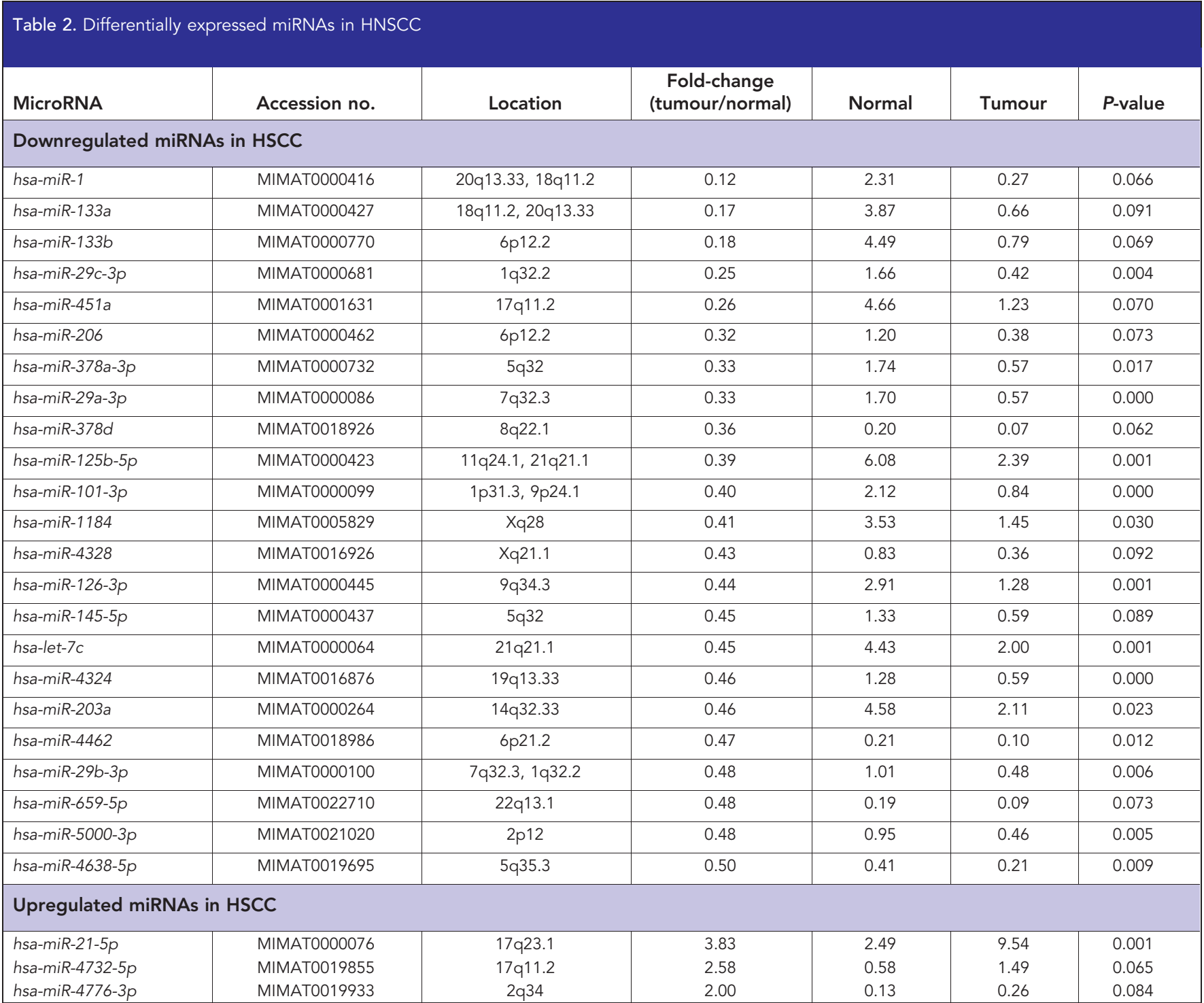

Therefore, we performed luciferase reporter assays in SAS cells to determine whether ESDN/DCBLD2 mRNA carried a target site for $m i R-451 a$. The TargetScan database predicted that one putative $m i R-451 a$ binding site existed in the $3^{\prime}$-UTR of the gene (position 2756-2762). We used vectors encoding either a partial wild-type sequence (including the predicted $m i R-451 a$ target site) or deletion-type sequence of the $3^{\prime}$-UTR of ESDN/DCBLD2 mRNA. We found that the luminescence intensity was significantly reduced by co-transfection with $m i R-451 a$ and the vector carrying the wild-type 3'-UTR of ESDN/DCBLD2 (Figure 4C).

Effects of ESDN/DCBLD2 silencing on cell proliferation, migration and invasion in cancer cell lines. To investigate the functional role of ESDN/DCBLD2 in HSCC cells, we performed loss-of-function studies using si-ESDN/DCBLD2 transfectants. First, we evaluated the knockdown efficiency of si-ESDN/DCBLD2 transfection in $\mathrm{FaDu}$ and SAS cells. Quantitative real-time RT-PCR and western blotting indicated that the siRNA effectively downregulated ESDN/DCBLD2 expression in both cell lines (Figure 5A).

In our functional analyses, XTT assays demonstrated that cell proliferation was not inhibited in $\mathrm{FaDu}$ si-ESDN/DCBLD2 transfectants compared with mock- or si-control-transfected cells (Figure 5B). In contrast, growth of SAS cell transfectants was slowed significantly. Transfection with si-ESDN/DCBLD2 inhibited both cell migration and invasion compared with mock- or si- control-transfected cells (Figure 5C and D), similar to the results observed for restoration of $m i R-451 a$.

\section{DISCUSSION}

Aberrant expression of miRNAs can upset tightly regulated RNA networks in normal cells, thereby promoting the development and progression of human cancers. Therefore, the first step in defining the contribution of miRNAs to oncogenesis is to identify the miRNAs that are differentially expressed in cancer cells. Our group has constructed miRNA expression signatures in various cancers, allowing us to identify tumour suppressive miRNAs and their targeted cancer pathways (Kikkawa et al, 2010; Nohata et al, 2011a; Yoshino et al, 2011).

In this study, we constructed a new HSCC miRNA expression signature because new human miRNAs had been added to the public databases after we undertook our initial analysis. In both our original signature of HSCC and the current one, miR-1/133a and $m i R-206 / 133 b$ clusters and the $m i R-29 s$-family were found to be downregulated. These findings demonstrate that our method of deriving an HSCC signature is reproducible. Moreover, our recent studies showed that the aforementioned miRNAs function as tumour suppressors via targeting several oncogenic pathways 
A

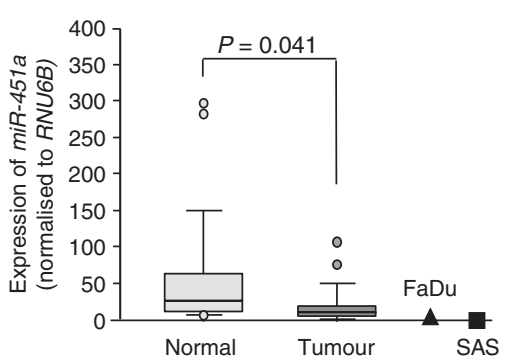

C

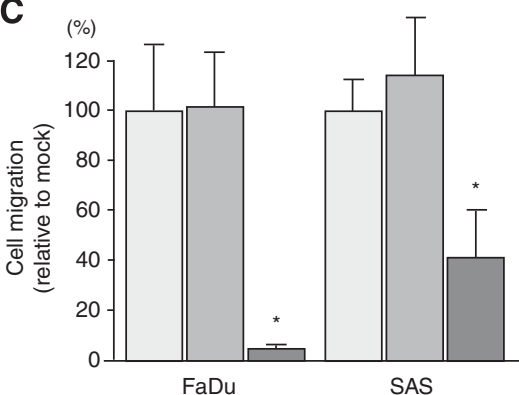

B Mock $\square$ Control $\operatorname{miR}-451 a$

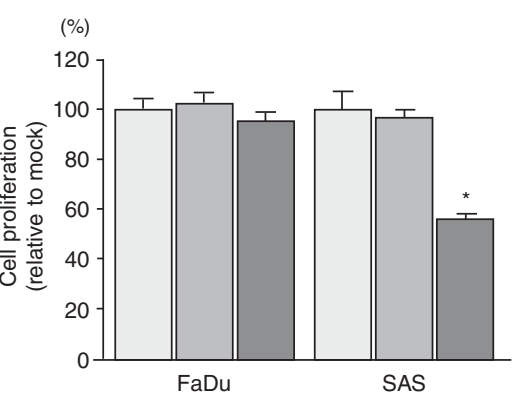

D

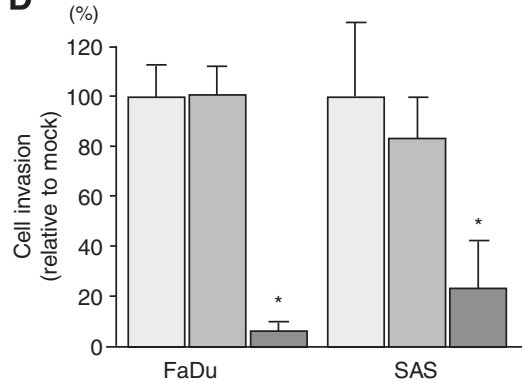

Figure 1. The functional significance of miR-451a in HSCC cells. (A) Expression levels of miR-451a in HSCC clinical specimens and cell lines. RNU6B was used as the internal control. (B-D) Effects of transfection of mature miR-451a in cancer cell lines. (B) Cell proliferation was determined with XTT assays in FaDu and SAS cell lines $72 \mathrm{~h}$ after transfection with $10 \mathrm{nM}$ of miR-451a, miR-control or mock transfection. (C) Cell migration activity determined with the migration assay. (D) Cell invasion activity was determined with the Matrigel invasion assay. ${ }^{\star} P<0.0001$.

Table 3. Candidate target gene for miR-451a

\begin{tabular}{|l|l|l|c|c|}
\hline Entrez gene ID & Gene symbol & Gene name & $\begin{array}{c}\text { Log } \text { ratio }_{\text {Lation }} \\
\text { (miR-451a/miR-control) }\end{array}$ \\
\hline 57405 & SPC25 & SPC25, NDC80 kinetochore complex component, homologue (S. cerevisiae) & $2 q 31.1$ & -3.55 \\
\hline 4282 & MIF & Macrophage migration inhibitory factor (glycosylation-inhibiting factor) & $22 q 11.23$ & -2.34 \\
\hline 131566 & ESDN/DCBLD2 & $\begin{array}{l}\text { Endothelial and smooth muscle cell-derived neuropilin-like molecule/discoidin, } \\
\text { CUB and LCCL domain containing 2 }\end{array}$ & $3 q 12.1$ & -1.81 \\
\hline 201725 & C4orf46 & Chromosome 4 open reading frame 46 & $4 q 32.1$ & -1.43 \\
\hline 231 & AKR1B1 & Aldo-keto reductase family 1, member B1(aldose reductase) & $7 \mathrm{q} 33$ & -1.25 \\
\hline
\end{tabular}
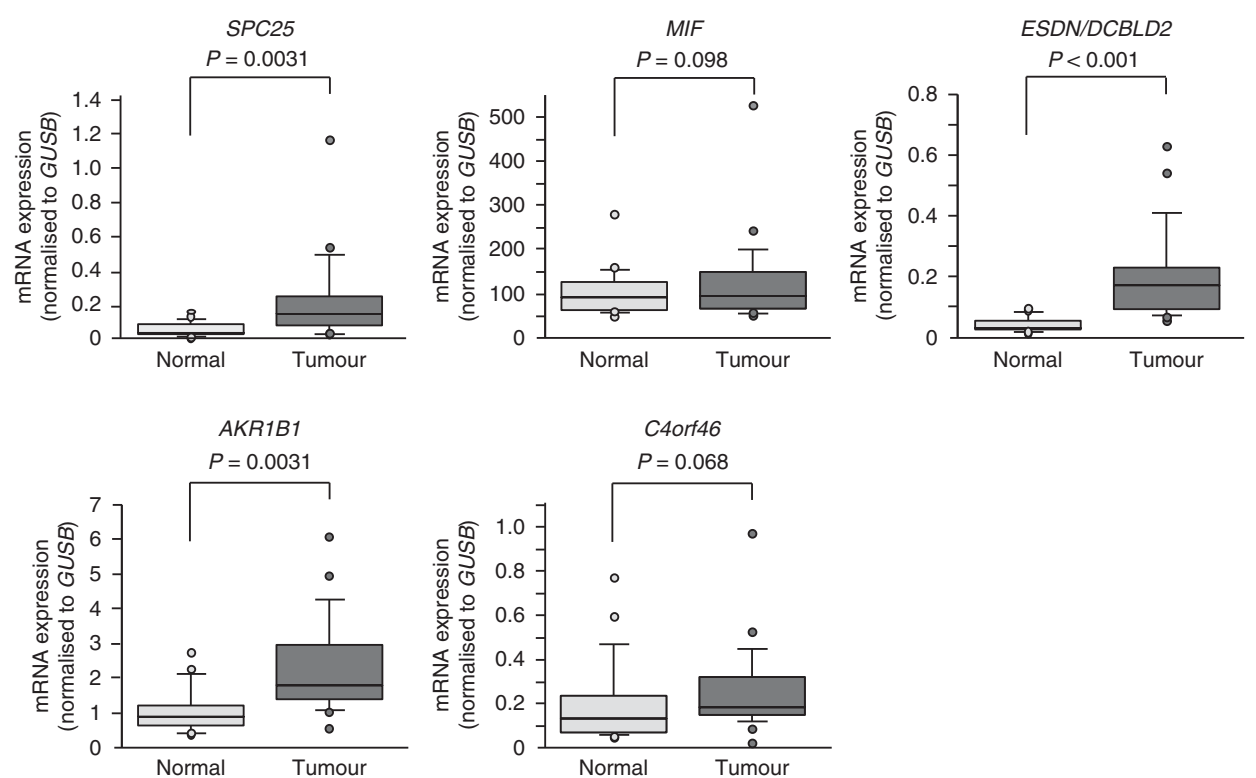

Figure 2. Expression levels of putative candidate target genes of miR-451a. The expression levels of five candidate genes (SPC25, MIF, ESDN/DCBLD2, AKR1B1 and C4orf46) were measured in HSCC clinical tissues by RT-PCR. GUSB was used as the internal control. 

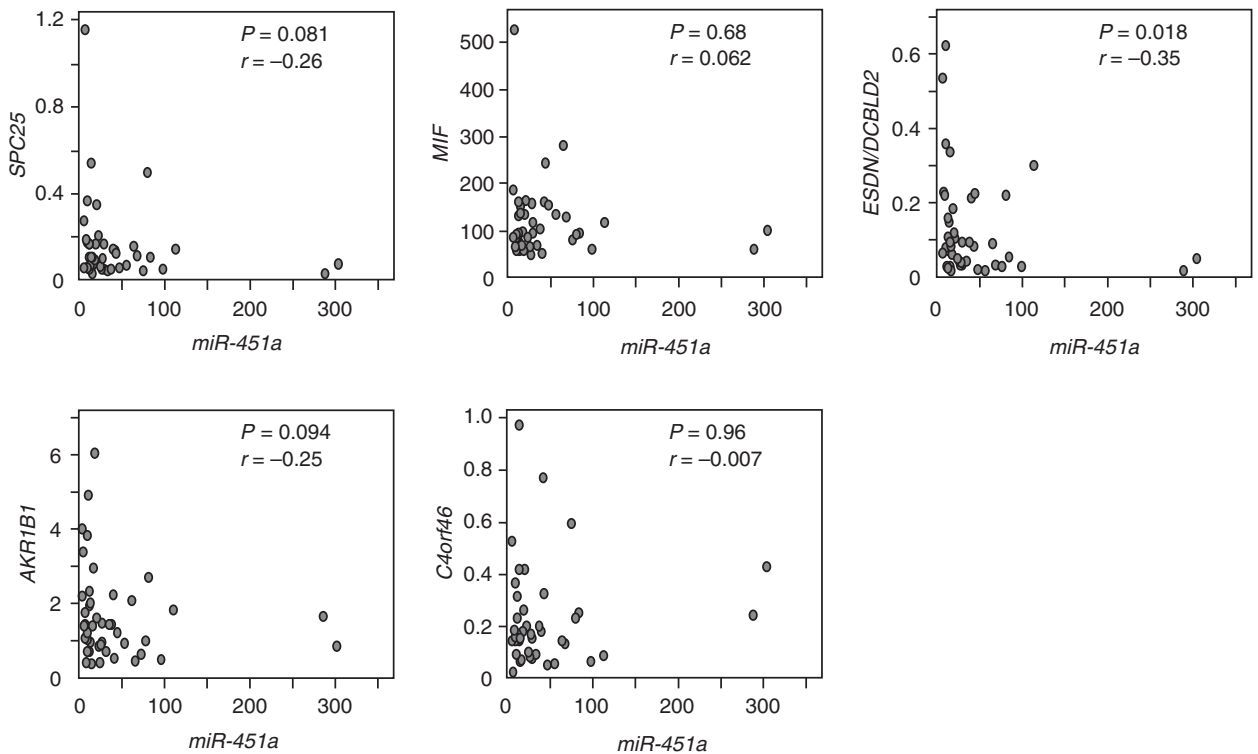

Figure 3. Correlation between the relative expression levels of miR-451a and target genes. Correlation between the relative expression levels of five candidate genes (y-axis; SPC25, MIF, ESDN/DCBLD2, AKR1B1 and C4orf46) and that of miR-451a (x-axis) was plotted in scatter diagrams. Spearman's rank test was used to evaluate the correlation between the expression of miR-451a and the target genes.
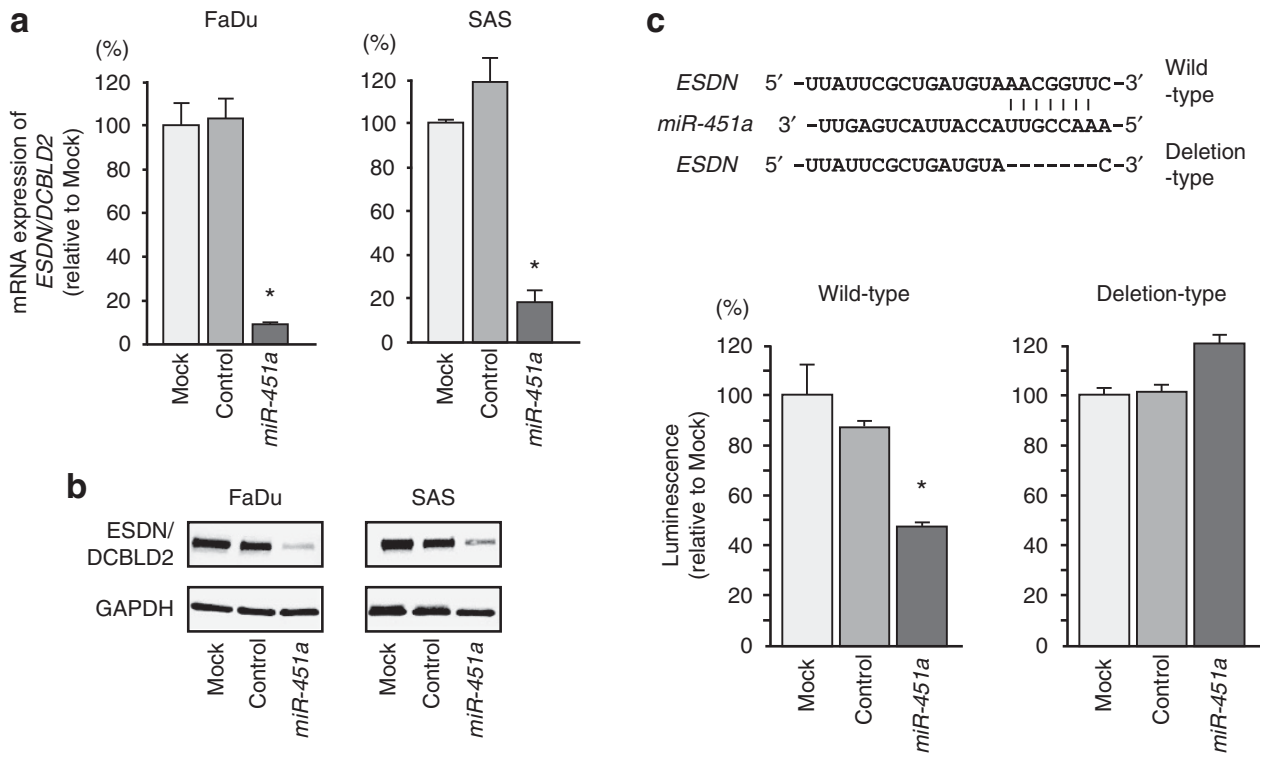

Figure 4. ESDN/DCBLD2 expression was directly regulated by miR-451a in cancer cells. (A) ESDN/DCBLD2 mRNA expression $72 \mathrm{~h}$ after transfection with miR-451a. GUSB expression was used for normalisation. (B) ESDN/DCBLD2 protein expression $72 \mathrm{~h}$ after transfection with miR-451a. GAPDH was used as a loading control. (C)The miR-451a binding site in the 3'-UTR of ESDN/DCBLD2 mRNA. Luciferase reporter assays used vectors that included (WT) or lacked (DEL) wild-type sequences of the putative miR-451a target site at position 2756-2762. Renilla luciferase values were normalised to firefly luciferase values. ${ }^{\star} P<0.01$.

(Nohata et al, 2012; Kinoshita et al, 2013). In our signature, $m i R-21$ was the most upregulated miRNA in HSCC tissues. Overexpression of $m i R-21$ was reported in several types of human cancers including HNSCC and $m i R-21$ is a key regulator of human oncogenic and metastatic signalling pathways (Pan et al, 2010; Fu et al, 2011). Therefore, elucidation of miR-21-regulated molecular targets and cancer pathways is an important study theme of the HSCC research fields.

Here, we focused on miR-451a. In this study, miR-451a was downregulated in HSCC clinical specimens. Several studies showed that epigenetic alterations such as DNA hypermethylation and histonmodification caused aberrant expression of miRNAs in cancer cells (Baer et al, 2013). Our preliminary study showed that expression of $m i R-451 a$ was not recovered by treatments of inhibitors of DNA methyltransferase or histone deacetylase in HNSCC cell lines (FaDu, SAS and HSC3). In contrast, the expression of miR-451a was significantly increased by treatment with 5-aza- $2^{\prime}$-deoxycitidine or sodium plenylbutyrate in non-small cell lung cancer (Wang et al, 2011). Promoter sequence of $m i R$ $451 a$ includes several transcription factor-binding sites (Pan et al, 2013), suggesting that $m i R-451 a$ is affected by various transcription factors. Future studies of chromatin immunoprecipitation assays are needed in HNSCC cells.

Analysis of miRNA signatures previously revealed that several miRNAs form clusters in the human genome and are downregulated together (Nohata et al, 2012; Kojima et al, 2013). Indeed, 

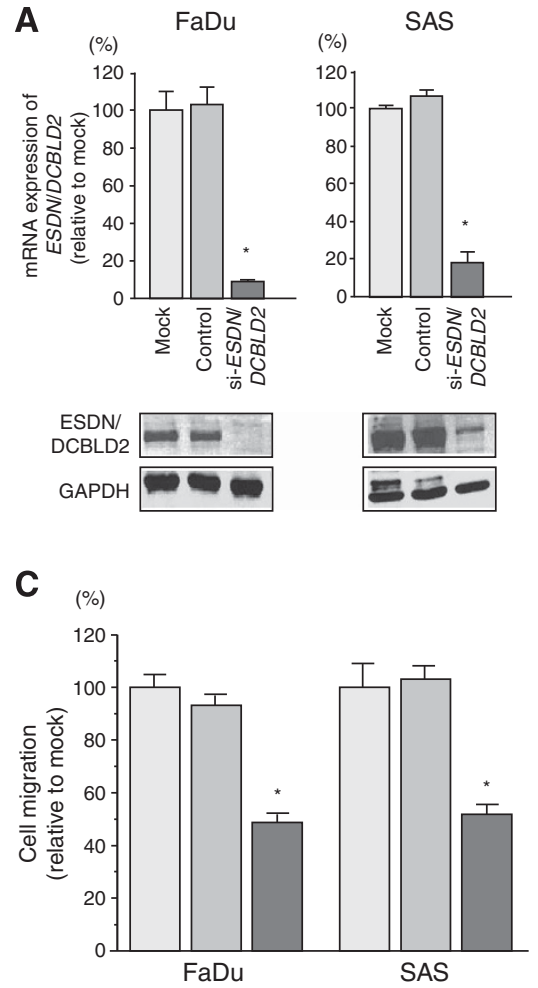
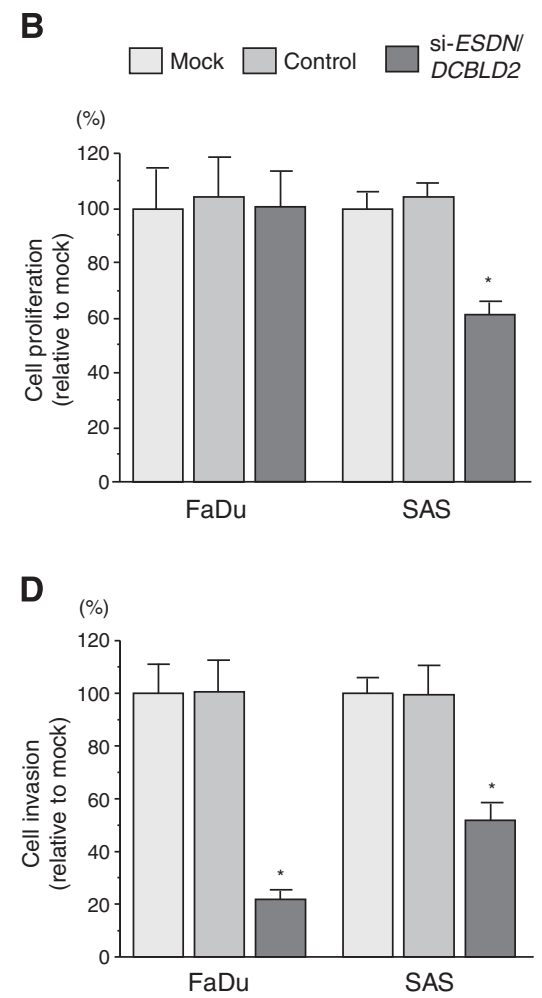

Figure 5. Effects of ESDN/DCBLD2 silencing by si-ESDN/DCBLD2 transfection on cancer cell lines. (A upper) ESDN/DCBLD2 mRNA expression $72 \mathrm{~h}$ after transfection with si-ESDN/DCBLD2. GUSB expression was used for normalisation. (A lower) ESDN/DCBLD2 protein expression $72 \mathrm{~h}$ after transfection with si-ESDN/DCBLD2. GAPDH was used as a loading control. (B-D) Effects of ESDN/DCBLD2 silencing on cancer cell lines. (B) Cell proliferation was determined with XTT assays in FaDu and SAS cell lines $72 \mathrm{~h}$ after transfection with $10 \mathrm{nM}$ of si-ESDN/DCBLD2, si-control or mock transfection. (C) Cell migration activity determined by the migration assay. (D) Cell invasion activity determined by the Matrigel invasion assay. ${ }^{\star} P<0.0001$

247 human miRNAs have been found to be located in 64 clusters at inter-miRNA distances of $<5000 \mathrm{bp}$ in the human genome (Yoshino et al, 2013). As demonstrated in our previous reports, while the seed sequences of $m i R-1$ and $m i R-133 a$ are different, the $m i R-1 / m i R-133 a$ cluster regulates common oncogenic genes, such as transgelin-2 and purine nucleoside phosphorylase in cancer cells (Yoshino et al, 2011; Nohata et al, 2011b; Yamasaki et al, 2012). In the human genome, miR-451a is located on chromosome 17q11.2, close to miR-144, indicating that these miRNAs form a clustered group. We investigate the expression levels of $m i R-144$ and $m i R-451 a$ and found that both were downregulated in cancer tissues. In fact, miR-451a expression was highly correlated with that of miR-144 (Supplementary Figure 1). These data suggest that expression of the $m i R-451 a / 144$ cluster is regulated as a single transcriptional unit in the human genome. In future studies, we will perform functional analysis of $m i R-144$ in HSCC to find novel networks in HSCC oncogenesis.

Our present data demonstrated that restoration of $m i R-451 a$ expression inhibited cancer cell migration and invasion, suggesting $m i R-451 a$ functions as a tumour suppressor in HSCC. Downregulation of $m i R-451 a$ was reported in other types of cancers, such as lung cancer, breast cancer, gastric cancer and brain tumours (Bandres et al, 2009; Wang et al, 2011; Bergamaschi and Katzenellenbogen, 2012; Tian et al, 2012). In lung cancer, ectopic miR-451a expression suppressed cancer cell proliferation and enhanced apoptosis via targeting of ras-related protein 14 (RAB14) and AKT signalling pathways (Wang et al, 2011). Inhibition of $\mathrm{PI} 3 \mathrm{~K} / \mathrm{AKT}$ pathways by $m i R-451 a$ was also reported in glioma and colorectal carcinoma cells(Tian et al, 2012; Li et al, 2013).

miRNAs are unique in their ability to regulate multiple proteincoding genes. Bioinformatic predictions indicate that miRNAs regulate $>60 \%$ of the protein-coding genes in the human genome.
Full understanding of the targets and signalling pathways in HSCC that are regulated by the $m i R-451 a$ family might contribute to our knowledge of HSCC metastasis. To identify the targets of tumour suppressive miRNAs and their pathways, we used gene expression data and in silico analyses in recent publications (Nohata et al, 2011a; Kinoshita et al, 2013). Using this approach, we successfully identified several tumour suppressive microRNA-mediated cancer pathways (Kinoshita et al, 2012a; Kojima et al, 2013). In this study, we found five genes that are putative $m i R-451 a$ targets (SPC25, $M I F, E S D N / D C B L D 2, C 4 o r f 46$ and AKR1B1). A recent study demonstrated that macrophage migration inhibitory factor (MIF) was a direct target of $m i R-451 a$ in nasopharyngeal carcinoma and that MIF controlled cancer cell growth and invasion (Liu et al, 2013). Our data also showed that expression of AKR1B1 (aldo-keto reductase family 1, member B1) and SPC25 (NDC80 kinetochore complex component) were upregulated in HSCC tissues. When we check the previous studies of these genes, overexpression of $A K R 1 B 1$ was reported in several types of cancers and promising drug target in solid cancer and leukaemias (Laffin and Petrash, 2012). Therefore, it is needed to investigate the $m i R-451 a-A K R 1 B 1$ mediated novel pathways to elucidate HSCC oncogenesis and metastasis. In contrast, there are few reports about expression of SPC25 and human cancers. Examination will be necessary about the functional role of SPC25 in human cancers in future.

Here, we focused on the ESDN/DCBLD2 gene as a tumour suppressive miR-451a target in HSCC because expression of the gene was most significantly upregulated in HSCC clinical specimens. We investigated tissue distribution of ESDN/DCBLD2 by immunohistochemical staining, and confirmed the expression of the protein in cancer lesions (Supplementary Figure 2). ESDN was initially cloned from human coronary artery and lung metastatic cancer cells (Kobuke et al, 2001). ESDN is a transmembrane 
protein and it contains discoidin and CUB domains similar to neuropilins (Kobuke et al, 2001). Recent study showed that ESDN promotes endothelial VEGF signalling and controls angiogenesis (Nie et al, 2013). However, no report has shown that ESDN modulates migration and invasion in cancer cells. Thus, our data are the first to report that ESDN was directly regulated by $m i R-451$ and contributed to cancer cell migration and invasion. Furthermore, to reinforce our data of HSCC, we measured expression status of miR-451a and ESDN/DCBLD2 in other sites of HNSCC. Downregulation of $m i R-451 a$ and upregulation of ESDN/DCBLD2 were confirmed in this analysis (Supplementary Figures 3 and 4). As such, tumour suppressive $m i R-451 a$ and ESDN might serve as therapeutic targets for cancer metastasis. Confirmation of these data using an in vivo mouse model is essential to support the conclusions of our in vitro results within the context of HSCC oncogenesis and metastasis.

\section{CONCLUSIONS}

Downregulation of $m i R-451 a$ was observed in a miRNA expression signature of HSCC. Restoration of $m i R-451 a$ significantly inhibited cancer cell migration and invasion, suggesting that miR-451a functioned as a tumour suppressor in HSCC. To the best of our knowledge, this is the first report demonstrating that tumour suppressive $m i R-451 a$ directly regulated ESDN/DCBLD2 in HSCC cells. Moreover, ESDN/DCBLD2 was upregulated in HSCC clinical specimens and contributed to cancer cell migration and invasion, indicating that it functioned as an oncogene. The identification of novel target oncogenes regulated by $m i R-451 a$ might lead to a better understanding of HSCC metastasis and the development of new therapeutic strategies to treat this disease.

\section{ACKNOWLEDGEMENTS}

This study was supported by the JSPS KAKENHI Grant Numbers 23592505, 24592590, 25462676 and 25861528.

\section{CONFLICT OF INTEREST}

The authors declare no conflict of interest.

\section{REFERENCES}

Baer C, Claus R, Plass C (2013) Genome-wide epigenetic regulation of miRNAs in cancer. Cancer Res 73: 473-477.

Bandres E, Bitarte N, Arias F, Agorreta J, Fortes P, Agirre X, Zarate R, Diaz-Gonzalez JA, Ramirez N, Sola JJ, Jimenez P, Rodriguez J, Garcia-Foncillas J (2009) microRNA-451 regulates macrophage migration inhibitory factor production and proliferation of gastrointestinal cancer cells. Clin Cancer Res 15: 2281-2290.

Bartel DP (2004) MicroRNAs: genomics, biogenesis, mechanism, and function. Cell 116: 281-297.

Bergamaschi A, Katzenellenbogen BS (2012) Tamoxifen downregulation of miR-451 increases 14-3-3zeta and promotes breast cancer cell survival and endocrine resistance. Oncogene 31: 39-47.

Carthew RW, Sontheimer EJ (2009) Origins and Mechanisms of miRNAs and siRNAs. Cell 136: 642-655.

Chan JY, Wei WI (2013) Current management strategy of hypopharyngeal carcinoma. Auris Nasus Larynx 40: 2-6.

Cooper JS, Porter K, Mallin K, Hoffman HT, Weber RS, Ang KK, Gay EG, Langer CJ (2009) National Cancer Database report on cancer of the head and neck: 10-year update. Head Neck 31: 748-758.

Esquela-Kerscher A, Slack FJ (2006) Oncomirs - microRNAs with a role in cancer. Nat Rev Cancer 6: 259-269.
Filipowicz W, Bhattacharyya SN, Sonenberg N (2008) Mechanisms of post-transcriptional regulation by microRNAs: are the answers in sight? Nat Rev Genet 9: 102-114.

Friedman RC, Farh KK, Burge CB, Bartel DP (2009) Most mammalian mRNAs are conserved targets of microRNAs. Genome Res 19: 92-105.

Fu X, Han Y, Wu Y, Zhu X, Lu X, Mao F, Wang X, He X, Zhao Y, Zhao Y (2011) Prognostic role of microRNA-21 in various carcinomas: a systematic review and meta-analysis. Eur J Clin Invest 41: 1245-1253.

Hall SF, Groome PA, Irish J, O'Sullivan B (2008) The natural history of patients with squamous cell carcinoma of the hypopharynx. Laryngoscope 118: 1362-1371.

Hobert O (2008) Gene regulation by transcription factors and microRNAs. Science 319: 1785-1786.

Iorio MV, Croce CM (2009) MicroRNAs in cancer: small molecules with a huge impact. J Clin Oncol. 27: 5848-5856.

Jemal A, Siegel R, Xu J, Ward E (2010) Cancer statistics, 2010. CA Cancer J Clin 60: 277-300.

Kikkawa N, Hanazawa T, Fujimura L, Nohata N, Suzuki H, Chazono H, Sakurai D, Horiguchi S, Okamoto Y, Seki N (2010) miR-489 is a tumour-suppressive miRNA target PTPN11 in hypopharyngeal squamous cell carcinoma (HSCC). Br J Cancer 103: 877-884.

Kinoshita T, Hanazawa T, Nohata N, Kikkawa N, Enokida H, Yoshino H, Yamasaki T, Hidaka H, Nakagawa M, Okamoto Y, Seki N (2012a) Tumor suppressive microRNA-218 inhibits cancer cell migration and invasion through targeting laminin-332 in head and neck squamous cell carcinoma. Oncotarget 3: 1386-1400.

Kinoshita T, Nohata N, Fuse M, Hanazawa T, Kikkawa N, Fujimura L, Watanabe-Takano H, Yamada Y, Yoshino H, Enokida H, Nakagawa M, Okamoto Y, Seki N (2012b) Tumor suppressive microRNA-133a regulates novel targets: moesin contributes to cancer cell proliferation and invasion in head and neck squamous cell carcinoma. Biochem Biophys Res Commun 418: 378-383.

Kinoshita T, Nohata N, Hanazawa T, Kikkawa N, Yamamoto N, Yoshino H, Itesako T, Enokida H, Nakagawa M, Okamoto Y, Seki N (2013) Tumoursuppressive microRNA-29s inhibit cancer cell migration and invasion by targeting laminin-integrin signalling in head and neck squamous cell carcinoma. Br J Cancer 109: 2636-2645.

Kobuke K, Furukawa Y, Sugai M, Tanigaki K, Ohashi N, Matsumori A, Sasayama S, Honjo T, Tashiro K (2001) ESDN, a novel neuropilin-like membrane protein cloned from vascular cells with the longest secretory signal sequence among eukaryotes, is up-regulated after vascular injury. J Biol Chem 276: 34105-34114.

Kojima S, Enokida H, Yoshino H, Itesako T, Chiyomaru T, Kinoshita T, Fuse M, Nishikawa R, Goto Y, Naya Y, Nakagawa M, Seki N (2013) The tumor-suppressive microRNA-143/145 cluster inhibits cell migration and invasion by targeting GOLM1 in prostate cancer. J Hum Genet. 59: 78-87.

Kwak PB, Iwasaki S, Tomari Y (2010) The microRNA pathway and cancer. Cancer Sci 101: 2309-2315.

Laffin B, Petrash JM (2012) Expression of the aldo-ketoreductases AKR1B1 and AKR1B10 in human cancers. Front Pharmacol 3: 104.

Li H-Y, Zhang Y, Cai J-H, Bian H-L (2013) MicroRNA-451 inhibits growth of human colorectal carcinoma cells via downregulation of Pi3k/Akt pathway. Asian Pac J Cancer Prev 14: 3631-3634.

Liu N, Jiang N, Guo R, Jiang W, He QM, Xu YF, Li YQ, Tang LL, Mao YP, Sun Y, Ma J (2013) MiR-451 inhibits cell growth and invasion by targeting MIF and is associated with survival in nasopharyngeal carcinoma. Mol Cancer 12: 123.

Nie L, Guo X, Esmailzadeh L, Zhang J, Asadi A, Collinge M, Li X, Kim JD, Woolls M, Jin SW, Dubrac A, Eichmann A, Simons M, Bender JR, Sadeghi MM (2013) Transmembrane protein ESDN promotes endothelial VEGF signaling and regulates angiogenesis. J Clin Invest 123: 5082-5097.

Nohata N, Hanazawa T, Enokida H, Seki N (2012) microRNA-1/133a and microRNA-206/133b clusters: dysregulation and functional roles in human cancers. Oncotarget 3: 9-21.

Nohata N, Hanazawa T, Kikkawa N, Sakurai D, Fujimura L, Chiyomaru T, Kawakami K, Yoshino H, Enokida H, Nakagawa M, Katayama A, Harabuchi Y, Okamoto Y, Seki N (2011a) Tumour suppressive microRNA-874 regulates novel cancer networks in maxillary sinus squamous cell carcinoma. Br J Cancer 105: 833-841.

Nohata N, Sone Y, Hanazawa T, Fuse M, Kikkawa N, Yoshino H, Chiyomaru T, Kawakami K, Enokida H, Nakagawa M, Shozu M, Okamoto Y, Seki N (2011b) miR-1 as a tumor suppressive microRNA targeting TAGLN2 in head and neck squamous cell carcinoma. Oncotarget 2: 29-42. 
Pan X, Wang R, Wang ZX (2013) The potential role of miR-451 in cancer diagnosis, prognosis, and therapy. Mol Cancer Ther 12: 1153-1162.

Pan X, Wang Z-X, Wang R (2010) MicroRNA-21: A novel therapeutic target in human cancer. Cancer Biol Ther 10: 1224-1232.

Takes RP, Strojan P, Silver CE, Bradley PJ, Haigentz Jr. M, Wolf GT, Shaha AR, Hartl DM, Olofsson J, Langendijk JA, Rinaldo A, Ferlito A. International H, Neck Scientific G (2012) Current trends in initial management of hypopharyngeal cancer: the declining use of open surgery. Head Neck 34: 270-281.

Tian Y, Nan Y, Han L, Zhang A, Wang G, Jia Z, Hao J, Pu P, Zhong Y, Kang C (2012) MicroRNA miR-451 downregulates the PI3K/AKT pathway through CAB39 in human glioma. Int J Oncol 40: 1105-1112.

Wang R, Wang ZX, Yang JS, Pan X, De W, Chen LB (2011) MicroRNA-451 functions as a tumor suppressor in human non-small cell lung cancer by targeting ras-related protein 14 (RAB14). Oncogene 30: 2644-2658.

Wang T, Zang WQ, Li M, Wang N, Zheng YL, Zhao GQ (2013) Effect of miR-451 on the biological behavior of the esophageal carcinoma cell line EC9706. Dig Dis Sci 58: 706-714.
Yamasaki T, Yoshino H, Enokida H, Hidaka H, Chiyomaru T, Nohata N, Kinoshita T, Fuse M, Seki N, Nakagawa M (2012) Novel molecular targets regulated by tumor suppressors microRNA-1 and microRNA-133a in bladder cancer. Int J Oncol 40: 1821-1830.

Yoshino H, Chiyomaru T, Enokida H, Kawakami K, Tatarano S, Nishiyama K, Nohata N, Seki N, Nakagawa M (2011) The tumour-suppressive function of miR-1 and miR-133a targeting TAGLN2 in bladder cancer. Br J Cancer 104: $808-818$

Yoshino H, Enokida H, Itesako T, Kojima S, Kinoshita T, Tatarano S, Chiyomaru T, Nakagawa M, Seki N (2013) Tumor-suppressive microRNA-143/145 cluster targets hexokinase-2 in renal cell carcinoma. Cancer Sci 104: 1567-1574.

This work is published under the standard license to publish agreement. After 12 months the work will become freely available and the license terms will switch to a Creative Commons AttributionNonCommercial-Share Alike 3.0 Unported License.

Supplementary Information accompanies this paper on British Journal of Cancer website (http://www.nature.com/bjc) 